DISTRIBUTION STATEMENT A. Approved for public release; distribution is unlimited.

\title{
Transitioning Results From Recent ONR WESTPAC Field Programs to Operational Use (IWISE Analysis Expansion)
}

\author{
Steven R. Ramp \\ Soliton Ocean Services, Inc. \\ 691 Country Club Drive \\ Monterey, CA 93924 \\ phone:(831)659-2230 fax: none email: sramp@solitonocean.com \\ Grant \#: N00014-12-1-0371
}

\section{LONG-TERM GOAL}

The long-term goal is to enhance our understanding of coastal oceanography by means of applying simple dynamical theories to high-quality observations obtained in the field. My primary area of expertise is physical oceanography, but I also enjoy collaborating with biological, chemical, acoustical, and optical oceanographers to work on interdisciplinary problems. I collaborate frequently with numerical modelers to improve predictive skill for Navy-relevant parameters in the littoral zone.

\section{OBJECTIVES}

The objective of this grant is to improve understanding of how the large-amplitude internal waves and tides in the northeastern South China Sea are generated via interaction of the barotropic tide with the ridges and islands in the Luzon Strait. In addition to the problem's inherent scientific interest, understanding the generation problem is essential for developing a forecast model to predict the wave characteristics in the deep basin and on the Chinese continental slope and shelf.

\section{APPROACH}

The approach is to particpate in a major ONR-sponsored field program in the Luzon Strait and northeastern South China Sea during 2010-2011. Called the Internal Waves in Straits Experiment (IWISE), the program is a logical follow-on to the Nonlinear Internal Waves Initiative (NLIWI) but will focus more closely on the generation problem, rather than on free propagation and wave dissipation during the earlier experiments. A large team of investigators from the U.S. and Taiwan is participating. Our primary collaborator in Taiwan is Prof. Y. J. Yang, now at National Taiwan University. He and Dr. Ramp were the co-leaders of cruises on Taiwanese vessels during the pilot study (June 2010) and the intensive observations program (IOP, August 2011). We have two key thrusts: Moored and shipboard observations south of Taiwan on the northern Heng-Chun ridge; and two far-field deep-water moorings near $18^{\circ} 30^{\prime} \mathrm{E}$ to monitor wave arrivals. The Heng-Chun site has not been previously explored, even though numerical studies suggest it is an important generation site. The far-field moorings will be combined with the PIES observations obtained by D. Farmer (UVic) and the source moorings of M. Alford (APL/UW) and J. Nash (OSU) to trace the progression of individual waves from the ridges to the deep basin. The program has an exciting numerical modeling component: We work especially closely with Oliver Fringer (Stanford) and Maarten Buijsman (NRLSSC). 


\section{Report Documentation Page}

Form Approved

OMB No. 0704-0188

Public reporting burden for the collection of information is estimated to average 1 hour per response, including the time for reviewing instructions, searching existing data sources, gathering and maintaining the data needed, and completing and reviewing the collection of information. Send comments regarding this burden estimate or any other aspect of this collection of information,

including suggestions for reducing this burden, to Washington Headquarters Services, Directorate for Information Operations and Reports, 1215 Jefferson Davis Highway, Suite 1204, Arlington

VA 22202-4302. Respondents should be aware that notwithstanding any other provision of law, no person shall be subject to a penalty for failing to comply with a collection of information if it

does not display a currently valid OMB control number.

1. REPORT DATE

30 SEP 2013

4. TITLE AND SUBTITLE

Transitioning Results From Recent ONR WESTPAC Field Programs to Operational Use (IWISE Analysis Expansion)

6. AUTHOR(S)

7. PERFORMING ORGANIZATION NAME(S) AND ADDRESS(ES)

Soliton Ocean Services, Inc,691 Country Club Drive,Monterey,CA,93924

9. SPONSORING/MONITORING AGENCY NAME(S) AND ADDRESS(ES)

12. DISTRIBUTION/AVAILABILITY STATEMENT

Approved for public release; distribution unlimited

13. SUPPLEMENTARY NOTES

14. ABSTRACT

15. SUBJECT TERMS

16. SECURITY CLASSIFICATION OF:

a. REPORT

unclassified b. ABSTRACT

unclassified c. THIS PAGE

unclassified
17. LIMITATION OF ABSTRACT

Same as Report (SAR)
3. DATES COVERED

00-00-2013 to 00-00-2013

5a. CONTRACT NUMBER

5b. GRANT NUMBER

5c. PROGRAM ELEMENT NUMBER

5d. PROJECT NUMBER

5e. TASK NUMBER

5f. WORK UNIT NUMBER

8. PERFORMING ORGANIZATION

REPORT NUMBER

10. SPONSOR/MONITOR'S ACRONYM(S)

11. SPONSOR/MONITOR'S REPORT NUMBER(S) 


\section{WORK COMPLETED}

The pilot study was quite successful and the results were described in last year's annual report and published in Ramp et al., [2012]. The IOP cruises were conducted during July - September 2011 from the OCEAN RESEARCHER III. These included a basin mooring deployment cruise during July (Figure 1), two cruises to the northern Heng-Chun Ridge during August, and a mooring recovery cruise during September. All the moorings were successfully recovered and the instruments returned full records of temperature $(\mathrm{T})$, salinity $(\mathrm{S})$, and current velocity $(\mathrm{u}, \mathrm{v})$. The preliminary results were presented at a workshop in Kaohsiung, Taiwan, during March 29-31, 2012. More advanced results were presented at seminars at National Taiwan University and National Sun Yat-sen University during November 2012. The data analysis from the IOP is nearly complete and a second manuscript is in advanced preparation [Ramp et al., 2013].

\section{RESULTS}

During August 2011, a combination of a mooring, three anchor stations, and underway CTDs were used to study wave generation and propagation (Figure 1). Many more mode-2 waves were observed, most commonly just after the ebb tide turned. The mooring frequently observed packets containing 45 waves each in contrast to the pilot study wave which was believed to be solitary. The waves were characterized by a westward core velocity of order $50 \mathrm{~cm} \mathrm{~s}^{-1}$ and eastward return flow exceeding this amount above and weaker below. The isotherms were displaced upward by order $50 \mathrm{~m}$ in the top half of the waves and downward by a similar amount in the lower half. The wave packets were also clearly visible in the EK500 backscatter data and were associated with spectacular surface signatures. At times, several rows of alternating slicks and breaking waves were visible on the sea surface. The packets mostly propagated westward but other waves were occasionally observed propagating SSW, indicating at least two active sources nearby. The along-crest distances were short, only a few kilometers.

The turbulent dissipation $(\varepsilon)$ was computed via the Thorpe scaling method. Large overturns of order $140 \mathrm{~m}$ with associated dissipation $\varepsilon$ order $10^{-3} \mathrm{~W} / \mathrm{kg}$ were observed in conjunction with two phenomena: roll-ups in the core of the mode-2 waves; and the high shear zone between the bottomtrapped tidal bore and the more quiescent water above (Figure 2). The vertically integrated energy flux due to the mode- 2 waves was order $30 \%$ of that due to the internal tide. The pressure work term u'p' was responsible for most of the flux in the wave, but zonal advection of kinetic energy was additionally important in the tide (Figure 3). The dissipation was very high, higher than that reported over deeper portions of the ridge [Alford et al., 2011] but smaller that the values in turbulent breaking mode-1 lee waves between Batan and Itbayat Island [Pinkel et al., 2012]. The high local dissipation and relatively small scales suggest the waves will not survive across the deep basin. Initial comparisons with the MITgcm model of flow across the ridge are encouraging: this work is ongoing.

\section{IMPACT/APPLICATION}

Turbulent breaking internal waves in the mid-thermocline region have a profound effect on navigation and acoustic propagation. 


\section{TRANSITIONS}

Results have been transitioned to NRL Stennis, CNMOC, and NAVO via a personal visit by the PI. The PI retains a courtesy appointment at the Naval Postgraduate School and has regular contact with the U.S. Navy via officer-students and faculty there.

\section{RELATED PROJECTS}

The ONR PhilSea10 project [Worcester et al., in press; Colosi et al., in press] may be useful in determining the internal wave propagation to the east of the Luzon Strait ridges. Please see associated annual reports for more details. The ONR/Taiwan NSC "sand dunes" project will investigate how nonlinear internal waves interact with the bottom. See separate annual report for details.

\section{REFERENCES}

Alford, M. H., J. A. MacKinnon, J. D. Nash, H. Simmons, A. Pickering, J. M. Klymak, R. Pinkel, O. Sun, L. Rainville, R. Musgrave, T. Beitzel, K.-H. Fu, and C.-W. Lu (2011), Energy flux and Dissipation in Luzon Strait: Two tales of two ridges, J. Phys. Oceanogr. 41, 2211-2222.

Colosi, J. A., L. J. Van Uffelen, B. D. Cornuelle, M. A. Dzieciuch, P. F. Worcester, B. D. Dushaw, and S. R. Ramp, 2012: Observations of sound speed fluctuations in the western Philippine Sea in the spring of 2009. J. Acous. Soc. Am., in press.

Pinkel, R., M. Buijsman, and J. M. Klymak, 2012: Breaking topographic lee waves in a tidal channel in Luzon Strait. Oceanography, 25, 160-165.

Ramp, S. R., Y. J. Yang, and F. L. Bahr, 2010: Characterizing the nonlinear internal wave climate in the northeastern South China Sea. Nonlin. Processes Geophys., 17, 481-498, doi:10.5194/npg-17481-2010.

Ramp, S. R., Y. J. Yang, D. B. Reeder, and F. L. Bahr, 2012: Observations of a mode-2 nonlinear internal wave on the northern Heng-Chun Ridge south of Taiwan. J. Geophys. Res., 117, C03043, doi:10.1029/2011JC007662.

Ramp, S. R., Y. J. Yang, D. B. Reeder, M. C. Buijsman, and F. L. Bahr, 2013: The flow over the northern Heng-Chun Ridge south of Taiwan. In preparation.

Worcester, P. F., R. K. Andrew, A. B. Baggeroer, J. A.Colosi, G. L. D’Spain, M. A. Dzieciuch, K. D. Heaney, B. M. Howe, J. N. Kemp, J. A. Mercer, R. A. Stephen, and L. J. Van Uffelen, 2012: The North Pacific Acoustic Laboratory (NPAL) deep-water acoustic propagation experiments in the Philippine Sea. J. Acous. Soc. Am., in press.

\section{PUBLICATIONS}

Ramp, S. R., "The flow over the northern Heng-Chun Ridge south of Taiwan." National Taiwan University, Taipei, Taiwan, November 2012

Ramp, S. R., "The flow over the northern Heng-Chun Ridge south of Taiwan." National Sun Yat-sen University, Kaohsiung, Taiwan, November 2012

Ramp, S. R., "Nonlinear internal waves in the South China Sea: Determining generation sites and mechanisms.” Stanford University, April 2013. 
Ramp, S. R., "The flow over the northern Heng-Chun Ridge south of Taiwan.” IWISE workshop, Seattle, WA, August 2013

Ramp, S. R., "Nonlinear internal waves in the South China Sea: A synopsis of recent results." NRL Stennis, September 2013 

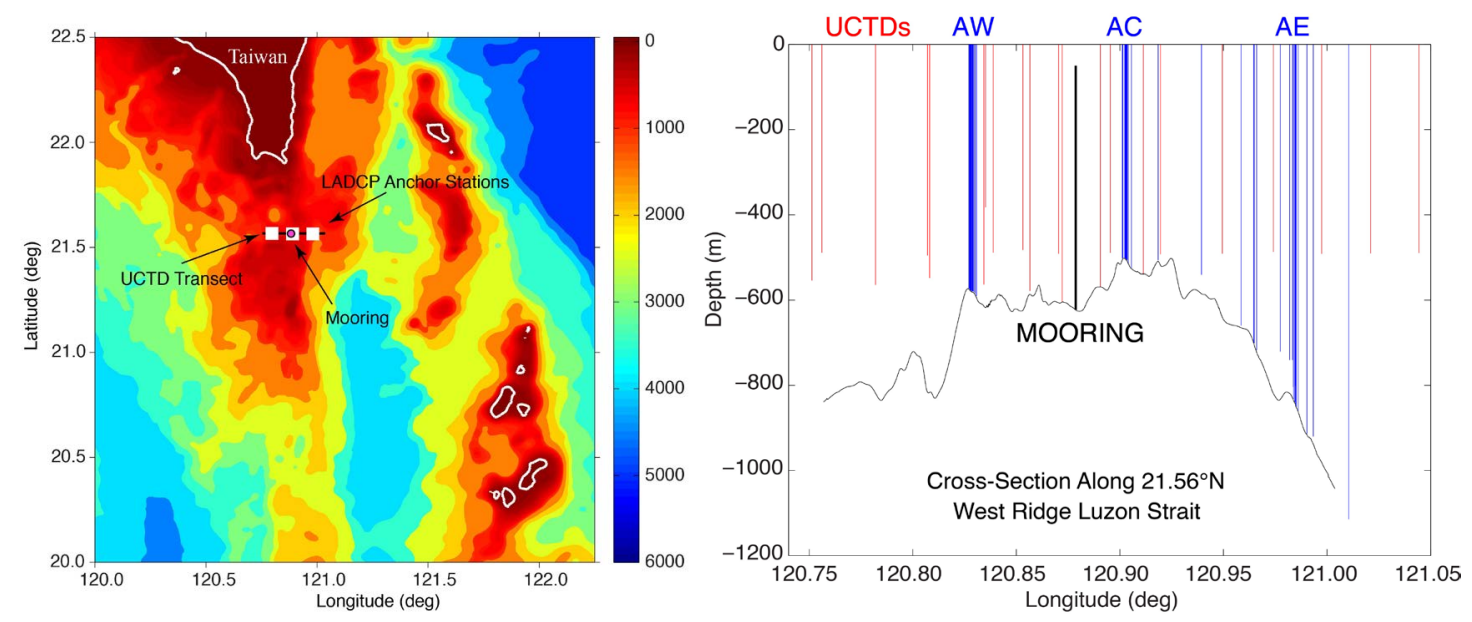

Figure 1. Location maps of the observations during the August 2011 field program. The 24-hour time series stations on the western, central, and eastern portion of the sill are indicated by $A W, A C$, and $A E$ respectively.

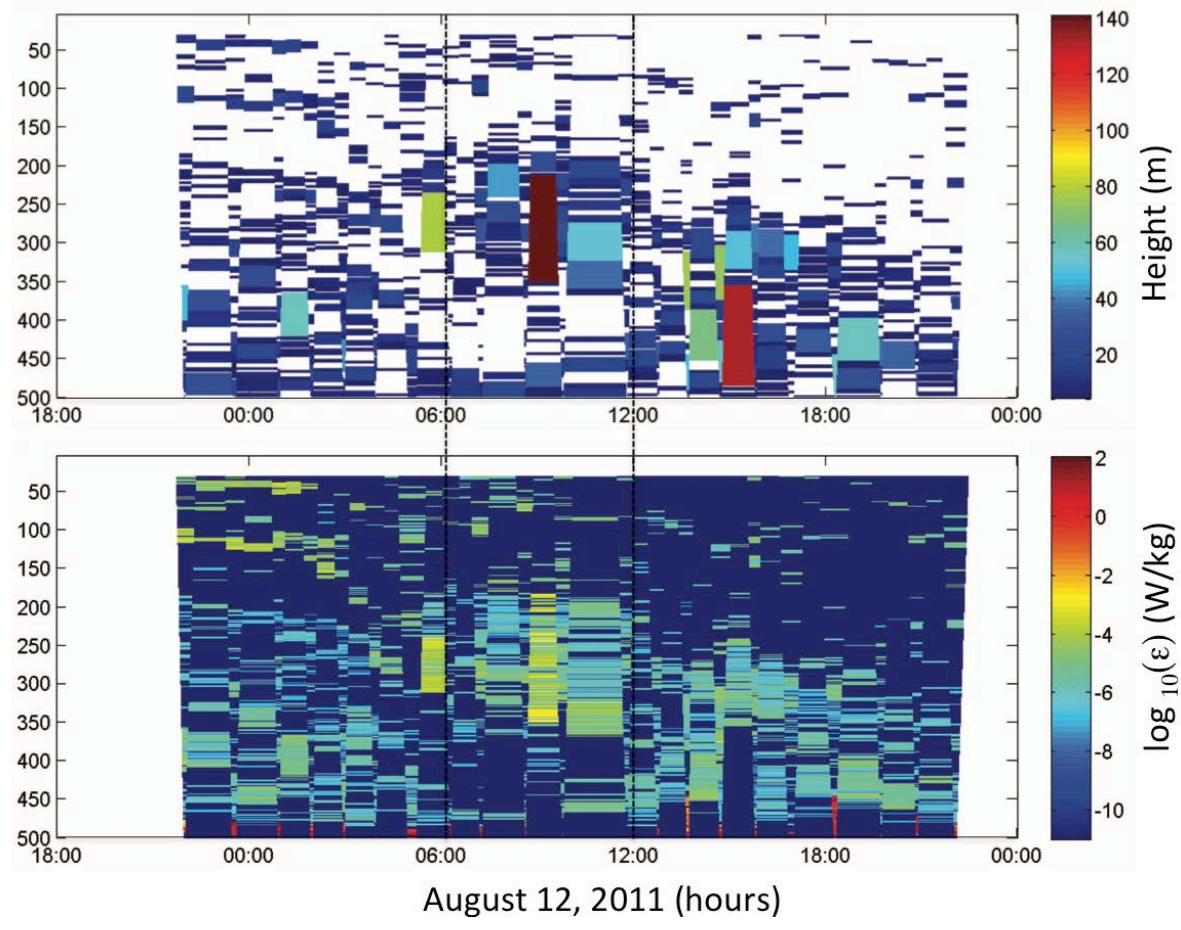

Figure 2. Overturn height and turbulent dissipation at station AC (see Figure 1 for location). The vertical dotted lines indicate the region occupied by the wave between $200-350 \mathrm{~m}$ depth. 

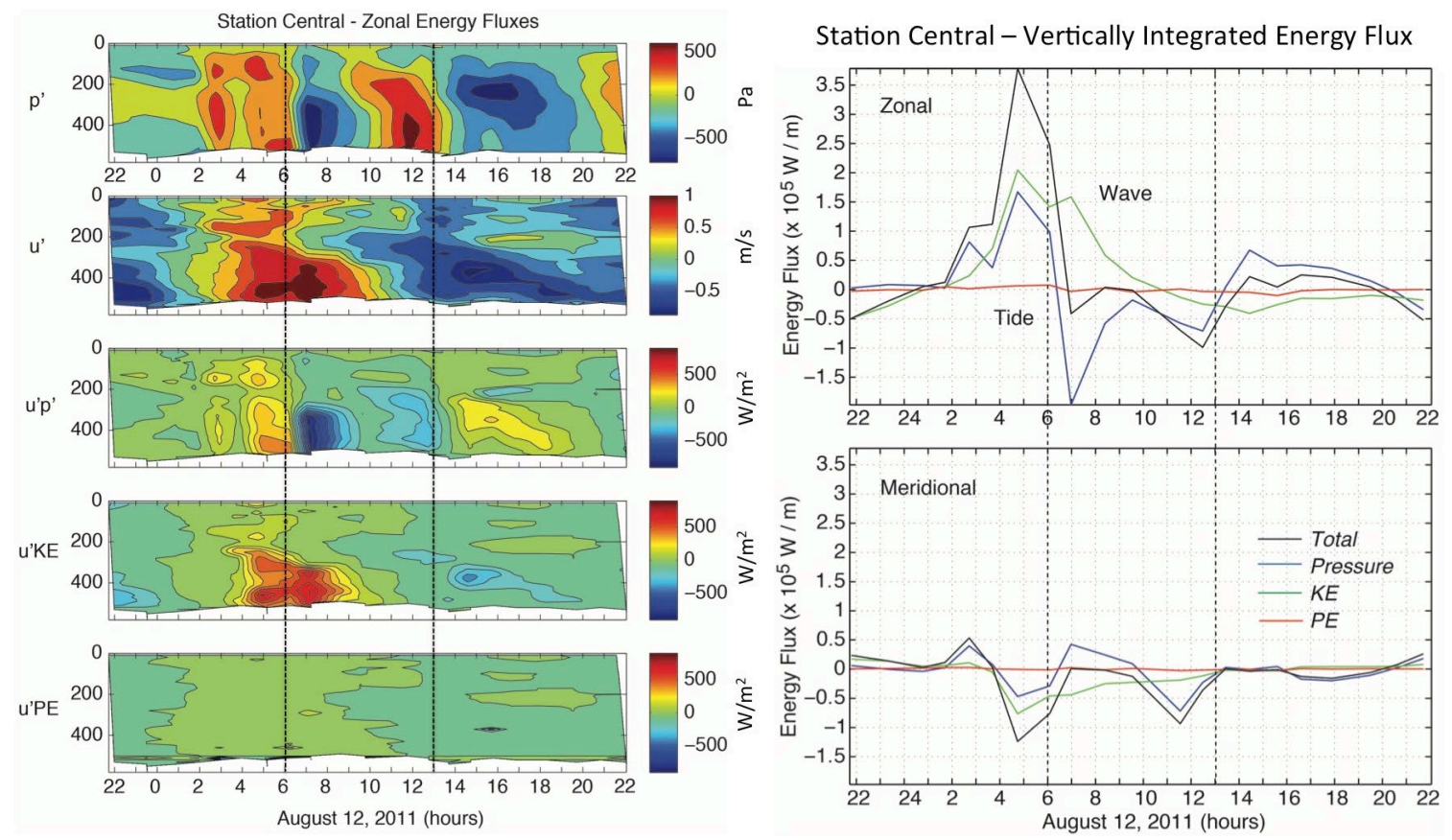

Figure 3. (left) Terms in the energy flux equation. From top to bottom, the baroclinic pressure perturbation, zonal velocity perturbation, pressure work term, and advection of kinetic and potential energy. (right) Vertically integrated values of the quantities in the bottom three panels of the left column. The solid black line is the total energy flux, the sum of the other three. The vertical dotted lines indicate the presence of the mode-2 internal wave. 